\title{
DRIVING ORGANIZATIONAL GROWTH THROUGH STRUCTURED SKILLS DEVELOPMENT
}

\author{
Noor Badariah Asan ${ }^{1}$, Zulkifli Shariff ${ }^{2}$, Jeffrey Bannister ${ }^{3}$ \\ ${ }^{1}$ Faculty of Electronic and Computer Engineering, University Teknikal Malaysia Melaka, Malaysia \\ ${ }^{2}$ Faculty of Engineering Technology, University Teknikal Malaysia Melaka, Malaysia \\ ${ }^{3}$ Competence Development-Orbitage Sdn. Bhd. Kuala Lumpur, Malaysia
}

\begin{abstract}
Organizations, particularly those that either rely on technology for their business or are offering services dependent on technology, need to ensure that their workforce have the right skills. Traditionally, skills development in organizations has been largely ad-hoc with programs coming from either equipment vendors or standalone, unrelated modules sourced from training providers. Additionally, many short training programs do not develop competence and/or have no effective assessment mechanisms. This has presented difficulties in tracking and managing competence across the workforce. This paper discusses a more coordinated approach where a structured skills development framework incorporating competence development and assessment is deployed to assist in driving the organization forward by ensuring the right competences are being developed effectively.
\end{abstract}

Keywords-Skills development, competence, organizational development

\section{INTRODUCTION}

It is acknowledged that one of the greatest assets and market differentiators that organizations have is their employees Error! Reference source not found.. Take for example, a mobile network operator. In a given country/market, they operate in a highly competitive environment where their competitors either offer the same or similar services, or are in a position to quickly replicate services. How can the organization build their brand value and differentiate their services from that of their competitor? One of the key ways is to develop their brand image on that of "quality" where they can retain customers through maintenance of this quality. To be able to achieve this, the operator must have the right people with the right skills. So how does the organization ensure that they develop and maintain the "right skills"? The first step is to identify as comprehensively as possible what competences are needed.

These should be aligned with where the organization is going to ensure that the correct competences are being developed Error! Reference source not found.. The selection of competences should be as comprehensive as possible to ensure that it covers all skills needed for the organization.

Next, competences need to be aligned to the organizational structureError! Reference source not found.. This is done by building a list of all unique job roles in the organization and then mapping competences to each role. Competences can be further qualified by defining a proficiency range \& descriptor for the competence so as individuals move up the organization, they can demonstrate greater proficiency in each competence required for their job role.

At this point, the organization has a map of the ideal situation, i.e. what are the requirements \& proficiency for each job role.
A skills gap analysis should be performed to map the skills of the individuals in each job role against the skills required to do the job. It is recommended that as much objectivity as possible is introduced at this stage to ensure the skills gaps highlighted are as close to reality as possible. Many organizations still rely very heavily on "subjective" peer and supervisor review. This is valuable and forms an essential part of a holistic review of individuals, however introducing objective testing, for example assessing practically that individuals are able to demonstrate competence at a given level of proficiency.

The outcomes of the skills gap is then used to develop a training plan. For the training to be effective, three critical elements must be present. Firstly, the training must be structured and reflective of the competence framework developed. Secondly, where possible, the training should be practical, competence-based where the focus is on what the participant "can do" rather than what they "know". Finally, the training must be assessed so that there is a validation that the competence has been developed. By conducting training in such a structured manner, it benefits both the individual and the organization. For the individual, there is a career progression charted through skills development; for the organization, it ensures that the right skills are being developed and that it has the ability to effectively achieve its strategic goals Error! Reference source not found.

The final stage of the process is to capture and manage the developed competence on an individual basis. By doing this, the organization can track the skills and thus obtain a "picture" of where they are in terms of the strategic plan. It also greatly facilitates the movement of staff within the organization since 
it is easy to see where competence overlaps are, facilitating lateral movements in the organizational structure.

\section{IDENTIFYING THE COMPETENCE NEEDED}

An important aspect of any competence plan is to correctly identify the competences that are needed. This should be closely aligned to the strategy of the organization to ensure that the skills being developed are the right skills. A comprehensive analysis of the organization's strategy should be conducted. Through discussion with stakeholders across the organization, a detailed "library" of competence is developed that should cover both technical and functional aspects of the job roles as well as highlighting underpinning knowledge needed.

Competences should be granular enough to effectively capture and allow differentiation of roles, while avoiding becoming too lengthy which will become difficult to manage.

The organization should also frame competence within the broader industry direction, rather than just looking inwards. This will assist in making the subsequent development process competitive with other industry players.

\section{BUILDING A SKILL DEVELOPMENT FRAMEWORK}

Once skills gaps have been identified through the mapping and assessment process, the gaps are addressed through training. It is critical that training is tied back to the skills gap process and to the initial competence framework for the organisation. This will ensure that the training has the most impact on addressing the needs of the organisation comprehensively. One problem that often occurs at this stage is that training is conducted in an ad-hoc manner, and often with ineffective or non-existent assessment post-training. This leads to great difficulty in tracking whether gaps are being filled. It is common here to have competences being developed via different training programs at different levels.

Another problem that often arises is that there is a "disconnect" between the human resources/training function and the team being trained. This is most common in cases where technical skills are being developed. The training department is tasked with sourcing effective training solutions to develop specific technical competences; however they do not have the skills to assess whether a given training program is suitable.

This is where a structured training framework can greatly assist the organisation Error! Reference source not found. The structure is built by involving all the stakeholders: HR/learning \& development, target teams, subject matter experts and training partners. By building a framework, there is a clear roadmap for staff to follow; by assessing each level of training \& skills development, the skills profile of individuals can be tracked and mapped back to the original skills gap assessment.
It is also critical that the training takes a competence-based approach where the emphasis is on "learning through doing" rather than an abstract or theoretical approach. Not only does this prove more effective in developing competence, it also creates a more conducive learning environment and greater motivation for learning amongst participants.

A focus on transferable and end-to-end skills should be incorporated as this provides the organisation with both more flexibility in staff movement and better "visibility" for staff with how their role fits into the organisational strategy Error! Reference source not found.. This is another reason why the involvement of all stakeholders into the definition of the framework is critical for success.

\section{ASSESSMENT IS KEY}

To be able to identify and fill skills gaps effectively, assessment is a central requirement. The closer the assessment results are to the real situation, the more successfully mapping can be performed.

For most organisations, assessment of competence is generally done via supervisor review. Often, this may be done in conjunction with a broader $360^{\circ}$ feedback mechanism. While valuable, this mechanism is vulnerable to subjectivity. There may potentially be a vast difference between the evaluation different individuals receive, depending on their relationship with their supervisor. This form of assessment is a valuable part of an overall profile, and in particular is useful for soft skills assessment. However, when assessing technical skills, it is more useful to introduce more objectivity into the assessment process. Technical skills lend themselves well to being assessed in this manner. There are a number of methods of conducting this type of objective assessment Error! Reference source not found. As an example, a hands-on "task" type assessment can be used where the subject is asked to perform a set of tasks, e.g. troubleshoot a fault, configure a piece of equipment, and then an assessment is made of the outcomes. Multiple choice and/or scenario based questions can also be effective here.

\section{MANAGING \\ AND \\ TRACKING}

\section{ORGANIZATIONAL GROWTH}

The long term benefit of this exercise is if the process is continual and to measure and enhance its effectiveness, having an efficient mechanism for tracking is key. This is particularly relevant when staff move around the organisation. As an example, good visibility of competence requirements for job roles allows individuals and stakeholders to see what is required to change job roles as well as being able to see which "moves" are more logical and/or easier, i.e. have a greater overlap of competence Error! Reference source not found.

However, when movements occur, captured competences should not be lost. If an individual moves to a new role, the competences that are no longer needed for the new role, but in which the individual is still competent should not be lost. In this manner, the organisation should have a better "map" of 
both the competences required for each role as well as the wealth of competences that exist within the organisation, whether directly required for their role or not Error! Reference source not found.

Probably the best way to manage this is using a computer based competence management system, particularly if it can integrate with existing corporate systems and integrate and interact with other human resource management systems.

\section{CONCLUSIONS}

It is critical that organizations, particularly those driven by technology, manage and develop their skills to meet their development strategy. This ensures that they have the correct skills in house and are ready to meet the challenges of the marketplace. A structured approach is needed to define a comprehensive competence framework and then assess the skills gaps across the workforce. Subsequently, a training plan should be implemented to ensure that the gaps are addressed.

Historically it has been very common in the assessment and skills gap phase to perform this via supervisor and/or peer review. While valuable, a better approach is to add as much "objective" assessment as possible, particularly for technical, "hard skills". This gives a clearer picture of skills for the individual.

When implementing the training plan, it should be structured and competence based, where the required skills are developed in-line with the competence requirements for organizational development, as well as following a clear roadmap that is visible to staff and forms a learning pathway for their career development.

Finally, assessment of training is key to success as it forms the final validation that skills have been developed. When performing this assessment, it should be structured to assess competence rather than knowledge. The focus should be on "what the individual can do" rather than "what the individual knows".

\section{REFERENCES}

[1] Economic Transformation Programmed, A roadmap for Malaysia Chapter 13: Communications Content and Infrastructure p33

[2] Yayasan Penelitian Dan Pengembangan Telematika Indonesia Seminar 21 ${ }^{\text {st }}$ November 2012: Strategic skills development for IT \& Telecoms Technical Staff:Malaysia - a case study Zulkifli Shariff, Paul Mather, Jeffrey Bannister

[3] Research Technology Management: The Journal of the Industrial Research Institute: October 2008 Aligning Competencies, Capabilities and Resources. Roger Smith; U.S. Army Simulation, Training, and Instrumentation.

[4] National Skills Development Corporation Human Resource and Skills Requirements in the IT \& ITES Industry Sector (2022): Study on mapping of human resource skill gaps in India till 2022 by R. Raghuttama
Rao \& M. Sairam IMaCS. http://smallb.in/sites/default/files/knowledge_base/Hu manResourceandSkillDevelopmentintheIT.pdf

[5] Government Initiatives in Human Capital Development: Developing a Highly-Skilled Workforce 2012 by YBhg Datuk Dr Pang Chau Leong Director General Department of Skills Development Malaysia

[6] Advances in Natural and Applied Sciences, 6(6): 882885, 2012 ISSN 1995-0772: Graduate Employability and Transferable Skills: A Review by Suriyani Muhamad Faculty of Management of Economics, Universiti Malaysia Terengganu http://www.aensiweb.com/anas/2012/882-885.pdf

[7] Scottish Qualifications Authority Publication Code:AA4147 Guide to Assessment November 2009 http://www.sqa.org.uk/files_ccc/GuideToAssessment. pdf

[8] How engineers become CEOs: implications for education and training. December 2008 Digital Networks - Product Services (DPS), Philips Industrial Activities by S. Goh, W. Coaker, D. Thorpe - Faculty of Engineering, University of Southern Queensland http://www.journalamme.org/papers_vol31_2/31299.p df

[9] A practical approach to competence management through metrics in an innovative organization by Ronald Begeer and Niloy Banerjee : Philips Industrial Activities 